\title{
Daily respiratory mortality and PM10 pollution in Mexico city
}

\section{To the Editor:}

We read with great interest the recent paper by TÈLlez-RoJo et al. [1] concerning the importance of considering place of death in daily respiratory mortality related to particles with a $50 \%$ cut-off aerodynamic diameter of $10 \mu \mathrm{m}$ (PM10) pollution in Mexico City. Other studies have reported associations between daily concentrations of PM10 and daily deaths [2]. These results may promote understanding of which persons are most sensitive to air pollution. Nevertheless, we have questions concerning the authors' conclusion on rate differences between deaths occurring inside medical units as opposed to those occurring elsewhere. The authors report a significant difference in relative risk (RR) between deaths in medical units and deaths out of medical units for an increase of $10 \mu \mathrm{g} \cdot \mathrm{m}^{-3}$ in the daily PM10. TÈLlEZ-RoJo et al. [1] hypothesized that those who died in medical units had received treatment and been isolated from outdoor pollution. But what was the nature of the association between air pollution and place of death? Was it a cause and effect statistical association?

Several factors need to be considered when comparing data with respect to place of death (in or out of a medical unit). Three parameters that probably influence whether subjects die in or out of a medical unit are sociodemographic considerations, concomitant illness, and the lag that may exist between exposure to air pollution and death.

Sociodemographic characteristics. Time series, which have been widely used in recent years, are based upon aggregated data. The statistical unit considered in this methodology is time, and the population serves as its own control group. This would tend to eliminate the influence of data concerning individual subjects, which is assumed to be constant over time.

When a time-series method is used, however, the comparison of the place of death is valid only if the entire population has the same probability of dying in a hospital or at home. This may not be the case in Mexico City, where one may easily imagine that people living in underprivileged sectors would have both greater exposure to pollution and more limited access to healthcare. The probability of such persons dying at home would therefore be higher.

Concomitant disease. FRIED et al. [3] found that, in people $65 \mathrm{yrs}$ of age, a state of functional or cognitive dependence, or the presence of certain illnesses, was often associated with a greater risk of dying at home than in a hospital. On the other hand, ZANOBETTI et al. [4] reported a correlation between PM10 exposure and hospitalization for respiratory disorders with an accentuated risk in patients with cardiovascular disease. Such illnesses play a role in the early hospitalization of subjects and should consequently influence the place of death.

The period of lag between exposure to air pollution and time of death. Tellez-Rojo et al. [1] studied deaths occurring with various lag times ranging from $1-5$ days after exposure to the high levels of air pollution. The risk of dying from a respiratory disorder outside of a hospital was higher for delay periods of $1-4$ days. It is noteworthy that for the 5-day lag, the results were significant, but in favour of death occurring in a medical unit. When the authors considered death from chronic obstructive pulmonary disease (COPD), the results did not agree with those of overall respiratory diseaserelated deaths, possibly due to the low number of COPD-related deaths.

The heterogeneous nature of the results may also be partially explained by the duration of the study period, which was only one year. In a study carried out in nine French cities, the period of time required to eliminate all temporal trend was 3-4 years [5]. Moreover, in a report on the delay between exposure to air pollution and time of death, ScHWARTz [6] concluded that the distribution of the lag times was more informative than the mean lag time.

Current results concerning the impact of air pollution are not clear with respect to the time factor. One study has shown that exposure to air pollution increases the very short-term risk of death in extremely fragile subjects, the life expectancy of whom is quite short in any event [7]. Because of this, beyond this short-term period, the risk of death in the rest of the population is reduced. This displacement of mortality, which has been designated "harvesting effect", was recently analysed by SCHWARTz [8], who found the importance of anticipated deaths to vary depending on the cause of death. From this standpoint, a time factor may exist between dying at home or in a hospital. Consequently, it is necessary to strictly control the lag times in investigations and to take the "harvesting effect" into account when estimating the risk of death related to atmospheric pollution.

In conclusion, time-series studies are perhaps not the most appropriate method of comparing places of death. Accordingly, even observed differences that are statistically significant should be considered with caution. A possible alternative solution would be to use a case-crossover design [9]. This method eliminates individual confounding factors by fixing the characteristics of the population sample and reduces the potential confounding effect of variable weather and influenza epidemics. The ideal design for such studies remains to be established. To take individual 
characteristics into account, longitudinal studies might be the most appropriate means of comparing places of death.

\section{Filleul*, S. Vandentorren*, I. Baldi*, J.F. Tessier*,\#}

*Laboratoire Santé Travail Environnement, Bordeaux, France. Fax: 33557571698 "INSERM U330, Bordeaux, France.

\section{References}

1. Téllez-Rojo MM, Romieu I, Ruiz-Velasco S, Lezana MA, Hernandez-Avila MM. Daily respiratory mortality and PM10 pollution in Mexico City: importance of considering place of death. Eur Respir $J$ 2000; 16 : $391-396$.

2. Pope CA, Dockery DW, Schwartz J. Review of epidemiological evidence of health effects of particulate air pollution. Inhal Toxicol 1995; 7: 1-18.

3. Fried TR, Pollack DM, Drickamer MA, Tinetti ME. Who dies at home? Determinants of site of death for community-based long-term care patients. $J$ Am Geriatr Soc 1999; 47: 25-29.

4. Zanobetti A, Schwartz J, Gold D. Are there sensitive subgroups for the effects of airborne particles? Environ Health Perspect 2000; 108: 841-845.

5. Quénel P, Cassadou S, Declercq C, et al. Surveillance épidémiologique Air \& Santé: Surveillance des effets sur la santé liés à la pollution atmosphérique en milieu urbain. Institut de Veille Sanitaire, Saint-Maurice, 1999.

6. Schwartz J. The distributed lag between air pollution and daily deaths. Epidemiol 2000; 11: 320-326.

7. McMichael AJ, Martens WJM. The health impacts of global climate change: grappling with scenarios, predictive models and multiple uncertainties. Ecosystem Health 1995; 1: 23-33.

8. Schwartz J. Harvesting and long term exposure effects in the relation between air pollution and mortality. Am J Epidemiol 2000; 151: 440-448.

9. Sunyer J, Schwartz J, Tobias A, Macfarlane D, Garcia J, Anto JM. Patients with chronic obstructive pulmonary disease are at increased risk of death associated with urban particle air pollution: a casecrossover analysis. Am J Epidemiol 2000; 151: 50-56. 